Article

\title{
In-Situ Measurement of Soil Permittivity at Various Depths for the Calibration and Validation of Low-Frequency SAR Soil Moisture Models by Using GPR
}

\author{
Christian N. Koyama ${ }^{1,2}, *$, Hai Liu ${ }^{3}$, Kazunori Takahashi ${ }^{2}$, Masanobu Shimada ${ }^{1,4}$, \\ Manabu Watanabe ${ }^{1}$, Tseedulam Khuut ${ }^{5}$ and Motoyuki Sato ${ }^{2}$ \\ 1 School of Science and Engineering, Tokyo Denki University, Ishizaka, Hatoyama-machi, Hiki-gun, \\ Saitama 350-0394, Japan; shimada@g.dendai.ac.jp (M.S.); 16hz001@ms.dendai.ac.jp (M.W.) \\ 2 Center for North East Asian Studies, Tohoku University, 41 Kawauchi, Sendai, Miyagi 850-8576, Japan; \\ takahashi-kazu@oyonet.oyo.co.jp (K.T.); sato@cneas.tohoku.ac.jp (M.S.) \\ 3 Institute of Electromagnetics and Acoustics, Department of Electronic Science, Xiamen University, \\ Xiamen 361005, China; liuhai8619@xmu.edu.cn \\ 4 Japan Aerospace Exploration Agency, Earth Observation Research Center, 2-1-1 Sengen, Tsukuba, \\ Ibaraki 305-8505, Japan \\ 5 School of Geology and Mining Engineering, Mongolian University of Science and Technology, 8th Khoroo, \\ Baga Toiruu, Ulaanbaatar-46/520, Mongolia; cee_0105@yahoo.com \\ * Correspondence: christian.koyama@outlook.com or 16hz010@ms.dendai.ac.jp; Tel.: +81-49-296-0319 \\ Academic Editors: Bruce Chapman, Paul Siqueira and Prasad S. Thenkabail \\ Received: 18 April 2017; Accepted: 8 June 2017; Published: 9 June 2017
}

\begin{abstract}
At radar frequencies below $2 \mathrm{GHz}$, the mismatch between the 5 to $15 \mathrm{~cm}$ sensing depth of classical time domain reflectometry (TDR) probe soil moisture measurements and the radar penetration depth can easily lead to unreliable in situ data. Accurate quantitative measurements of soil water contents at various depths by classical methods are cumbersome and usually highly invasive. We propose an improved method for the estimation of vertical soil moisture profiles from multi-offset ground penetrating radar (GPR) data. A semi-automated data acquisition technique allows for very fast and robust measurements in the field. Advanced common mid-point (CMP) processing is applied to obtain quantitative estimates of the permittivity and depth of the reflecting soil layers. The method is validated against TDR measurements using data acquired in different environments. Depth and soil moisture contents of the reflecting layers were estimated with root mean square errors (RMSE) on the order of $5 \mathrm{~cm}$ and 1.9 Vol.-\%, respectively. Application of the proposed technique for the validation of synthetic aperture radar (SAR) soil moisture estimates is demonstrated based on a case study using airborne L-band data and ground-based P-band data. For the L-band case we found good agreement between the near-surface GPR estimates and extended integral equation model ( $\left.{ }^{2} \mathrm{EM}\right)$ based SAR retrievals, comparable to those obtained by TDR. At the P-band, the GPR based method significantly outperformed the TDR method when using soil moisture estimates at depths below $30 \mathrm{~cm}$.
\end{abstract}

Keywords: BIOMASS; CMP; L-band; P-band; permittivity; Pi-SAR-L2; soil moisture; vadose zone

\section{Introduction}

In situ measurements of soil permittivity (i.e., soil moisture content) are a prerequisite for the calibration and validation of synthetic aperture radar (SAR) soil moisture retrieval algorithms. Despite the difficulties arising from different sensing depths of ground-based sensors and incoming 
SAR signals (Figure 1), the standard approach for in situ soil moisture measurements is the use of time domain reflectometry (TDR) or frequency domain reflectometry (FDR) probes. Depending on the sensor type and length of the rods, the measurement depth usually varies between $5 \mathrm{~cm}$ and $15 \mathrm{~cm}$. Most studies ignore the problems of mismatching measuring depths and utilize this kind of in situ data from low frequency L-band [1-3] to high frequency C- [4-6] and even X-band SAR data [7-9]. While the obtained information is generally not fully suitable for high frequency SAR data due to the limited penetration into the soil, in some cases it might also be misleading for L-band data when the soil is dry and the penetration depth exceeds the sensor depth. However, with the advent of the European Space Agency (ESA) BIOMASS mission [10], the first ever P-band SAR earth observation satellite, the classical methods to determine "ground truth" soil moisture will become completely unsuitable. Considering the much higher penetration capabilities at the $435 \mathrm{MHz}$ center frequency, information about the vertical soil moisture distribution, rather than the surface soil moisture information alone, becomes crucial. Especially the knowledge of both the permittivity and depth of wet soil layers will be of great value for future calibration and validation studies at the P-band. Figure 1 shows the theoretical relation between the radar frequency and penetration depth for a one-way path $\delta_{p}$ as calculated approximately by

$$
\delta_{p} \cong \frac{\lambda \sqrt{\varepsilon^{\prime}}}{2 \pi \varepsilon^{\prime \prime}}
$$

where $\lambda$ is the wavelength in free space and $\varepsilon=\varepsilon^{\prime}-\mathrm{j} \varepsilon^{\prime \prime}$ is the relative complex permittivity, for a range of soil moisture values. As can be seen, the theoretical penetration depth exceeds the measuring depth of the soil moisture probes for water contents below 20 Vol.- $\%$ at L-band and for all moisture conditions at P-band.

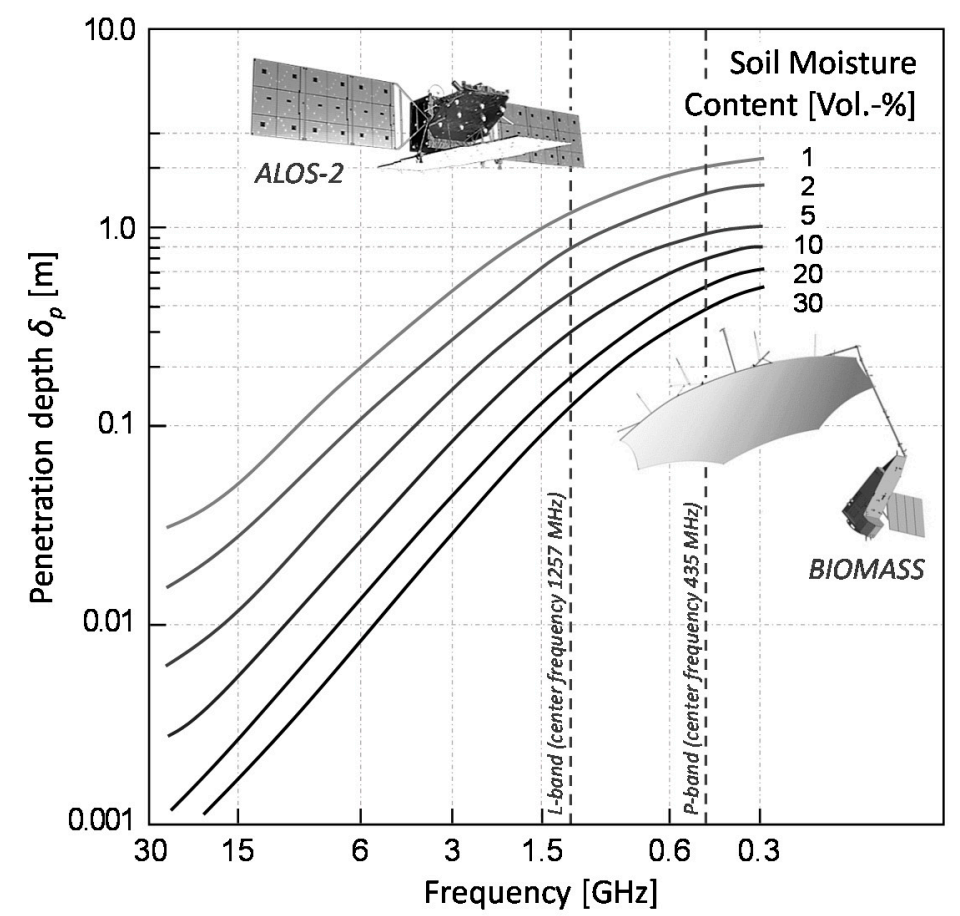

Figure 1. Frequency dependency of the synthetic aperture radar (SAR) penetration depth $\delta_{p}$ for different soil moisture states ranging from 1 to $30 \mathrm{Vol} . \mathrm{\%}$.

Measuring soil moisture at various depths by means of classical methods (i.e., gravimetry, FDR, TDR, and capacitance measurements) is cumbersome and not feasible in a spatially distributed manner in coordination with satellite passes. At best, only very limited point information is available from continuous monitoring stations with sensors installed at several fixed depths. To overcome this 
problem, we propose an improved method for the fast and robust quantitative estimation of vertical soil moisture profiles by using ground penetrating radar (GPR). The method, based on the well-known common mid-point (CMP) technique [11], allows for acquiring a vertical permittivity profile, taking into account the real subsurface soil layer structure, in just under $2 \mathrm{~min}$.

Within the last two decades, GPR has matured to one of the standard methods to investigate geological and pedological subsurface structures. In principal, GPR records electromagnetic (EM) waves reflected from the boundaries of subsurface materials having different dielectric properties. Usually, GPR data is collected in a common-offset configuration in which the spacing between the transmitting (Tx) and receiving ( $\mathrm{Rx}$ ) antenna is fixed for all the recorded traces [12]. In low attenuation media, this method allows for high-resolution imaging of the shallow subsurface, where the imaging depth and resolution depends on the antenna frequencies. In the literature, GPR has been widely discussed as a non-destructive measurement technique for soil moisture data [13-17]. However, it is a highly intricate task to calculate the permittivity by using common-offset data alone, and even with the use of a priori knowledge, e.g., the reflector depth, the results are usually rather of a qualitative nature [18-20], and hence far from being suitable for serving as a "ground truth" for SAR data.

CMP measurements have been widely used in both seismic and GPR surveys to investigate the vertical velocity profiles [11,21-23]. In the CMP method, one antenna is used only for transmitting the radar signal while another one is used as the receiver. The transmitter and receiver are moved apart from their "common mid-point" and multiple traces are recorded synchronously at increasing antenna offsets. The method was originally developed in the 1950s and first published by Mayne [24]. The CMP approach has many advantages over common-offset measurements in terms of more accurate, quantitative parameter estimation from GPR data. The first of the two main advantages is probably a significant improvement in the signal-to-noise ratio. By stacking the reflection signals recorded from the same reflection point multiple times, the energy of the reflected signal can be increased. This is because the reflected waves are coherent while at the same time the energy of the noise is decreased due to its randomness or residual moveout. Coherent noise components like reflections from objects on the surface can be reduced by two-dimensional f-k filtering prior to stacking because of their distinct different velocity [25].

The second advantage is the possibility of calculating the root mean square (RMS) velocity. Using the Dix formula [26], the interval velocities for multiple soil layers can subsequently be obtained from the RMS velocities allowing for accurate estimation of the permittivity at the reflecting point. In the presence of a water saturated layer, like a groundwater aquifer, it can easily be identified by its RMS velocity due to the sharp contrast compared to the unsaturated zone [22,27]. Several studies have discussed the effect of the velocity analysis on the stacked CMP gather for quantitative retrieval of the subsurface soil water content [28-30].

In this study, we developed an advanced processing scheme for quantitative soil moisture estimation from CMP gather to not only improve the understanding of the vertical soil moisture distribution and groundwater conditions, but also to acquire in situ "ground truth" data for calibration and validation of the soil moisture models and related remote sensing products. The rest of the paper is organized as follows. After briefly reviewing the principles of microwave soil moisture measurements in the next section, Section 3 addresses the materials used and elucidates in detail the advanced CMP method for in situ soil permittivity measurements at various depths. The validation of the method and demonstration of the application to the SAR data are discussed in Section 4. The conclusion of the study is given in Section 5.

\section{Principles of Soil Moisture Retrieval from Microwave Measurements}

To set the foundation for the discussion of the advanced GPR processing in the following chapter, we shall briefly review the foundations of microwave permittivity measurements in this section. The determination of soil relative permittivity (apparent dielectric constant) and related volumetric moisture content by GPR and TDR is based on the measurement of the traveling speed of a fast 
voltage pulse. While GPR measures the travel time between the Tx/Rx antennas and a reflector target, TDR measures the travel time along a parallel transmission line inserted in the soil. The speed of a voltage pulse (microwave) decreases with increasing dielectric constant of the material in contact with the transmission line. Due to the significant difference between the dielectric constant of water and of the other constituents of a soil texture, i.e., air and mineral particles, etc., the speed of travel of the electromagnetic (EM) wave in the transmission lines in soils is essentially dependent on its volumetric moisture content. The real-part of the permittivity of water in the microwave frequency range is $\sim 81$, while that of air is 1 . The permittivity of the soil particles usually range between 4 and 7 [12]. Thus, by evaluating the travel time of the pulse it is possible to compute the real part of the permittivity of the soil from

$$
v=\frac{c}{\sqrt{\varepsilon_{r} \mu}}
$$

where $v$ is the velocity of the EM wave in the soil, $c$ is the velocity of the EM wave in free space, $\varepsilon_{r}$ is the relative permittivity of the soil, and $\mu$ is the relative magnetic permeability of the soil.

Since for most soils $\mu$ is nearly equal to 1 , we can conveniently estimate $\varepsilon_{r}$ from the measured $v$ by

$$
\varepsilon_{r}=\left(\frac{c}{v}\right)^{2}
$$

Volumetric soil moisture content $m_{v}$ can then be estimated by the function $m_{v}\left(\varepsilon_{r}\right)$ as e.g., proposed in the form of empirical polynomial relationships by [31]. However, it is important to note that the fact that the EM waves in GPR are unguided as compared with the waves guided by a TDR sensor, renders the accurate determination of the travel time much more complicated.

The amplitude of the radar reflection is a function of the contrast in $\varepsilon$ across the reflecting boundary which is given by the reflection coefficient $\Gamma$ as

$$
\Gamma=\frac{\sqrt{\varepsilon_{1}}-\sqrt{\varepsilon_{2}}}{\sqrt{\varepsilon_{1}}+\sqrt{\varepsilon_{2}}}
$$

where $\varepsilon_{1}$ and $\varepsilon_{2}$ depict the permittivity of the upper and lower soil layer, respectively. Since water has the highest permittivity of all the components commonly found in a soil, the received GPR reflections can largely be attributed to vertical contrasts in soil moisture content $[13,28]$. In fact, variations in soil texture alone are usually not sufficient to give rise to a large reflection coefficient [32], while they may well be associated to vertical changes in the soil water distribution due to the different water retention properties in different soil horizons.

Despite the immense increase in GPR applications, TDR is still the standard approach for in situ soil moisture measurements. Among the main advantages of the well-established TDR technique are the simple operation and its high mobility as compared to the GPR equipment. However, it is important to note that the TDR probes cannot be used under many conditions of natural surfaces when e.g., the rods cannot penetrate the soil properly because the matrix is too hard or because stones and/or roots hinder accurate measurements. Even under relatively favorable conditions the rods can bend easily and break eventually. The existence of macro pores can hamper the accuracy significantly due to insufficient contact of the rods to the soil matrix. Moreover, and most importantly, measuring vertical soil moisture distributions by TDR is a cumbersome exercise requiring highly invasive and labor-intensive excavations.

\section{Materials and Methods}

In this section, the advanced GPR processing will be discussed in detail followed by the SAR related parameter estimation issues. First, an overview of the experimental strategy, location corresponding sensors, and instruments used shall be provided. Most of the GPR measurements were conducted in the frame of in situ surface parameter measurements for airborne Synthetic Aperture Radar acquisitions on bare agricultural fields (Arahama, Japan) and sand beaches (Yuriage, Japan) 
close to Sendai city in the Miyagi Prefecture, Japan [2,33]. These measurements were carried out shortly before and shortly after the overflights of the Japanese Polarimetric Interferometric Synthetic Aperture Radar type L-band 2 (Pi-SAR-L2) operated by the Japanese Aerospace Exploration Agency (JAXA). Four to six CMP data sets were acquired on each day using the $500 \mathrm{MHz}$ antennas. After these measurements, the vertical soil moisture distribution was measured by TDR to compare CMP estimates with the TDR measured water content at respective depths. A pit was dug at the CMP location and the TDR soil moisture values were taken at $5 \mathrm{~cm}$ intervals. In addition to these campaign measurements, we use GPR/CMP measurements carried out in (i) Iwanuma close the southern border of Miyagi, (ii) at the arid land research center of Tottori University at the Japanese Sea coast, as well as (iii) in the Bulgan region in Mongolia that is approximately $300 \mathrm{~km}$ west of Ulaanbaatar. The latter was conducted in the frame of an ALOS-2 Cal/Val measurement campaign in August 2014. However, due to the very strong ionospheric disturbance, the dual polarization ALOS-2 data acquired at that time was rendered unsuitable for quantitative parameter estimation. Consequently, no space borne SAR data is considered in this paper.

The microwave measurement equipment used in this study were TRIME Pico64 TDR probes (IMKO GmbH, Ettlingen, Germany) and shielded 500 MHz RAMAC GPR antennas (MALÅ Geosciences, Malå, Sweden). The surface roughness was measured by using a pin-meter with a sampling spacing of $5 \mathrm{~mm}$. For validation of the reflecting layer depth, we used in situ information obtained from the drilling cores, Pürkhauer samples, and pits. The various types of measurements are summarized in Figure 2.

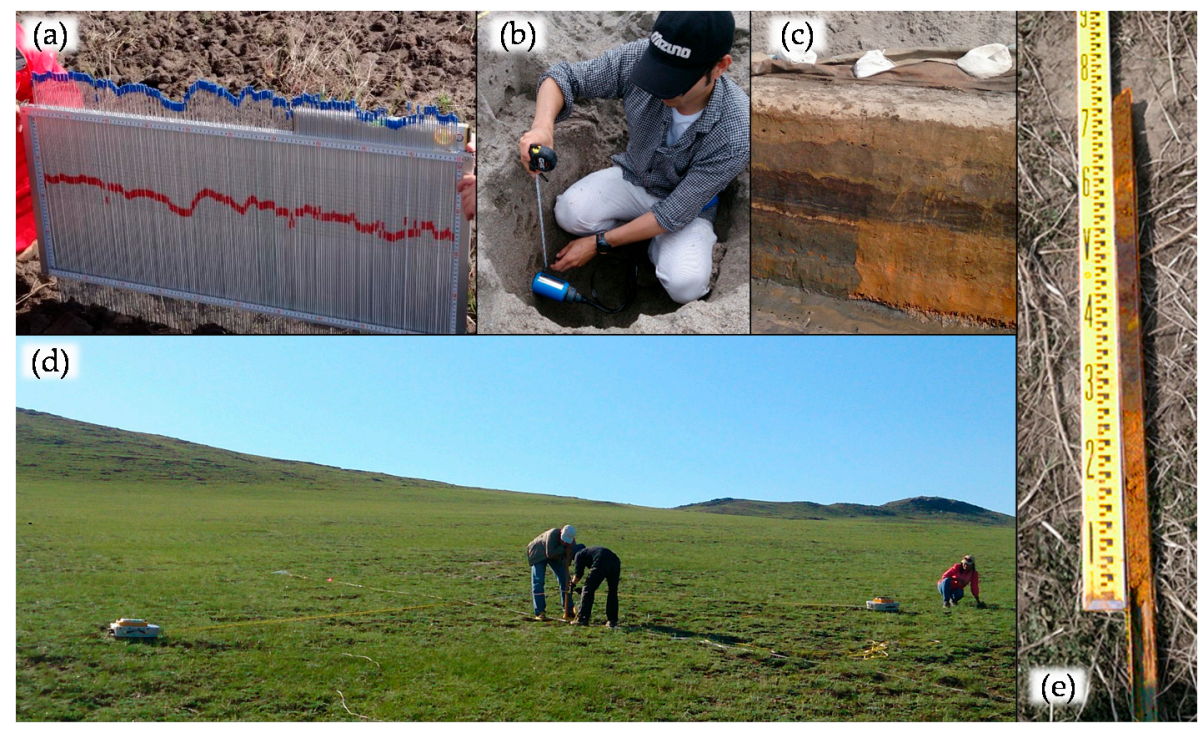

Figure 2. Various ground measurements used in this study including: (a) surface roughness measurement by pin-meter; (b) time domain reflectometry (TDR) soil moisture measurements; (c) depth measurement in a pit; (d) common mid-point (CMP) measurement in Mongolia, and (e) depth measurement using Pürkhauer.

\subsection{GPR Soil Moisture Estimation by Means of CMP Velocity Analysis}

As discussed in the introduction, CMP can improve the benefit of GPR for hydrological research tremendously by allowing for quantitative estimations of hydraulic soil parameters. Figure 3 shows a schematic representation of the CMP method with transmitting and receiving antennas located symmetrically about a CMP position while measuring their common mid-point at different antenna offsets. 


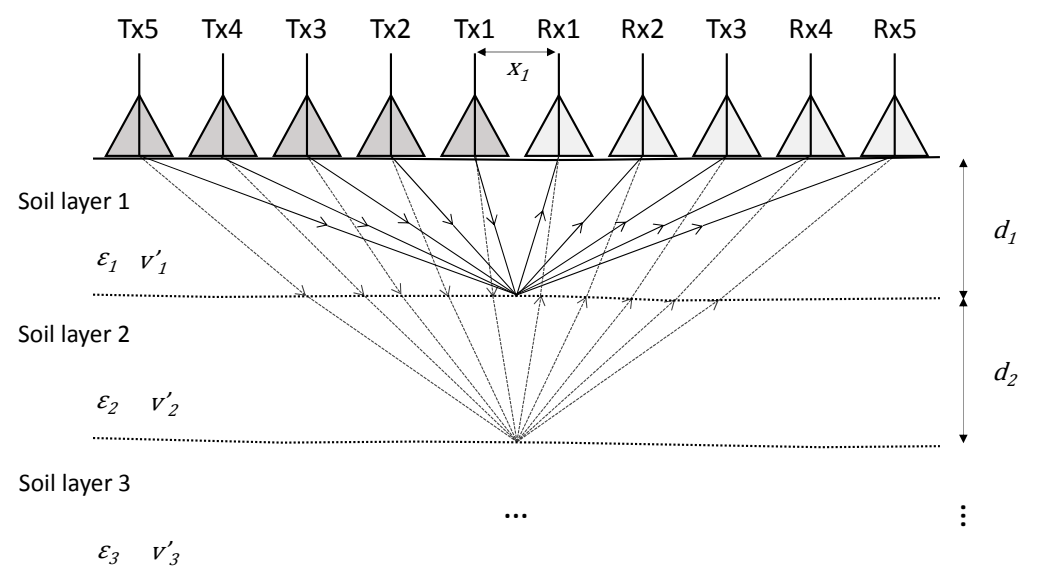

Figure 3. Sketch of the CMP method for soil moisture estimation at multiple depths.

Traditionally this is performed by stepwise movement of the Tx and Rx antennas away from each other manually $[28,29,34,35]$. Today, with the increasing availability of arrayed antenna GPR systems, such CMP gather can in principal be acquired without having to move the GPR system at all. One such advanced multi-channel GPR is the "Yakumo" operated exclusively by our group [36]. The system was developed by Tohoku University in cooperation with Mitsui Shipbuilding and Engineering (Okayama, Japan) and has eight Tx and eight Rx antennas with a maximum antenna separation of approximately $2 \mathrm{~m}$. However, in such a setup the number of observable traces as well as the length of the profile length is limited by the array configuration. To improve the acquisition speed of classical CMP using two separated antennas, we developed a method in which the antennas are placed at their maximum separation at the start of the measurement. The traces are then recorded automatically, triggered by a hip chain encoder, while the antennas are pulled simultaneously towards the mid-point. The sketch of this method is shown in Figure 4. In this fashion, a full CMP measurement with $2 \mathrm{~cm}$ trace intervals and $10 \mathrm{~m}$ profile length can be achieved in just under $2 \mathrm{~min}$. In principal, only one person is needed to carry out the procedure. Compare this to the time and effort required by the manual step-by-step movement, which moreover increases the risk of errors in the antenna positioning, especially when the intervals are very small.

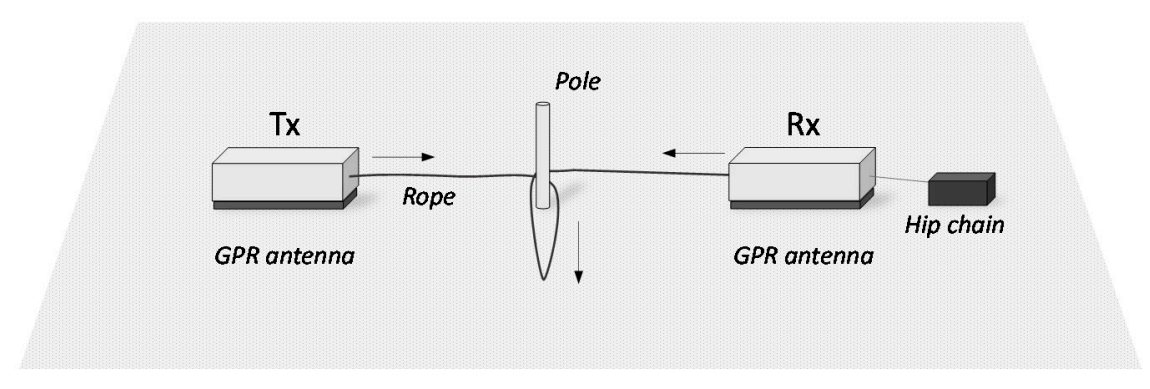

Figure 4. Sketch of the semi-automated CMP acquisition procedure.

Based on the assumption that the soil medium is virtually homogeneous and horizontally layered, the two-way traveling time of the reflection signal from the subsurface boundary allows for computing the radar velocity with

$$
t\left(x_{i}\right)=\frac{2 \sqrt{\left(\frac{x_{i}}{2}\right)^{2}+d^{2}}}{v}
$$

where $t$ is the travel time, $x_{i}$ is the antenna offset in the $i$-th channel, $d$ is the depth of the reflector, and $v$ is the radar velocity. 
The travel time of a reflection in a CMP gather, thereby, can be expressed as a function of the antenna offset and RMS velocities. This allows for obtaining a vertical velocity profile of the subsurface media from a CMP dataset by means of velocity analysis. The velocity spectrum has been commonly used to estimate the propagation velocity in both seismic and GPR data processing. It is a robust method that displays the stacked coherency of the received signals in different channels along the hyperbolic curves defined by a range of trial velocities [11]. One of the common approaches to measure the coherency in CMP processing is semblance [37] which is computed from the real amplitude of the radar signal. Semblance $S$ is a function of the two-way zero-offset travel time and the trial velocity as given by

$$
S=\frac{\left(\sum_{i=1}^{n} f\left(t_{i}\right)\right)^{2}}{n \sum_{i=1}^{n} f_{i}^{2}\left(t_{i}\right)}
$$

where $f_{i}\left(t_{i}\right)$ is the amplitude of the radar signal acquired in the $i$-th channel at the two-way travel time $t_{i}$.

As a GPR signal usually exhibits oscillating characteristics due to the limited frequency bandwidth, each reflection event will result in several responses in the corresponding velocity spectrum. This phenomenon significantly hampers the determination of the correct arrival times [38,39]. To overcome this problem, we convert the radar signal to the analytical signal by using the Hilbert transform. Subsequently, the fact that the envelope of the radar signal has only one peak makes it simple to pick the arrival of the reflection signal. Thus, we can use the semblance of the analytical signal to calculate the velocity spectrum with

$$
S_{a}=\frac{\left|\sum_{i=1}^{n} f\left(t_{i}\right)+j g_{i}\left(t_{i}\right)\right|^{2}}{n \sum_{i=1}^{n}\left|f\left(t_{i}\right)+j g_{i}\left(t_{i}\right)\right|^{2}}
$$

where $f(t)$ and $j g(t)$ denote the real and imaginary part of the analytical signal, respectively. This can be interpreted as the ratio of the output total power to the input total power.

It is important to note that the semblance analysis uses normalization. Hence the semblance is powerful if the analysis is focused on the correlation of the individual phases and also small amplitude reflections shall be adapted. However, at the same time this causes additional uncertainty in the velocity analysis because a given reflection may generate a series of semblance peaks. To compensate for this effect and to make the soil moisture estimation more robust, next we calculate the non-normalized cross-correlation sum within a time gate following the semblance stacking across the CMP gather. The non-normalized cross-correlation is given by

$$
C C\left(t(0), v_{s t}\right)=\frac{1}{2} \sum_{t}\left\{\left[\sum_{i=1}^{n} f_{i, t(i)}\right]^{2}-\sum_{i=1}^{n} f_{i, t(i)}^{2}\right\}=\frac{1}{2} \sum_{t}\left[s_{t}^{2} \sum_{i=1}^{n} f_{i, t(i)}^{2}\right]
$$

where $v_{s t}$ is the semblance stacking velocity and $C C$ can be interpreted as half the difference between the output energy of the stack and the input energy. It should be emphasized that the non-normalized cross-correlation takes into account the true amplitudes and thus adapts only high amplitude reflections [29]. In this way, the chance of picking up unwanted multiple reflections is greatly reduced.

Figure 5 shows an example of a velocity spectrum of a CMP gather with $500 \mathrm{MHz}$ antennas obtained by using the combined semblance and non-normalized cross-correlation sum. In most natural situations, the EM wave velocity decreases with increasing depth in a soil as a result of an increase in the water content. However, inverted conditions are not that uncommon and can be observed especially in soils with low water retention capability after precipitation events. Also, sandwich-like structures where wetter soil layers are interrupted by a dryer layer or vice versa can be found in many places. 


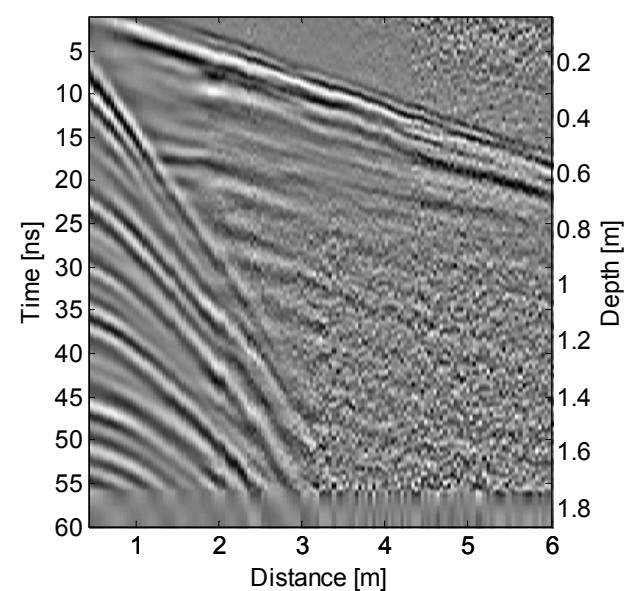

(a)

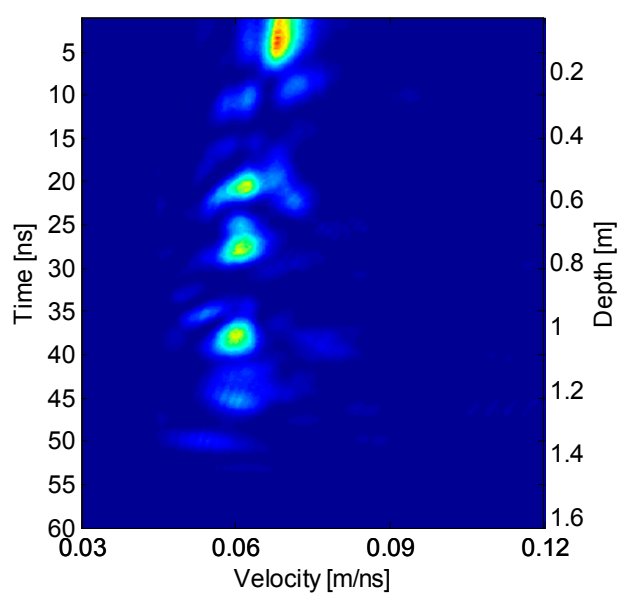

(b)

Figure 5. (a) Stacked CMP gather acquired on an agricultural field in Miyagi prefecture; (b) The resulting velocity spectrum with four distinct reflection layers.

\section{Dielectric Constant Retrieval at Various Depths}

The main advantages of the CMP method compared to the TDR method is probably the fact that it allows for estimating the water content for multiple reflecting layers and thus can provide hydrologists a vertical soil moisture profile by taking just one measurement. However, it should be noted that the vertical water content estimations cannot be selected freely by the user, but is defined by the natural conditions in the soil, i.e., the number and depth of reflecting layers with large enough contrast in the permittivity.

The RMS velocity is approximately equivalent to the normal move-out (NMO) velocity assuming that the medium from the surface to the boundary is homogeneous when the subsurface is composed of multiple horizontal layers. However, the NMO velocity is usually highly affected by homogeneities of the medium and the dip of the boundary. Thus, we use only the RMS velocity to make the parameter estimation more robust. To estimate the correct permittivity and depth of each layer, the RMS velocities have to be corrected to interval velocities. The interval velocity $v_{\text {int }}$ can be calculated by the Dix formula [26] as

$$
v_{\text {int }, n}=\sqrt{\frac{t_{0, n} v_{r m s, n}^{2}-t_{0, n-1} v_{r m s, n-1}^{2}}{t_{0, n}-t_{0, n-1}}}
$$

where $v_{i n t, n}$ is the interval velocity of layer $n, v_{r m s, n}$ is the RMS velocity down to the lower boundary of layer $n, v_{r m s, n-1}$ is the RMS velocity down to the lower boundary of layer $n-1, t_{0, n}$ is the two-way travel time down to the lower boundary of layer $n$, and $t_{n-1}$ is the two-way travel time down to the lower boundary of layer $n-1$.

The corresponding thickness of layer $n$ can then be estimated by

$$
d_{n}=\frac{v_{\text {int }, n}\left(t_{0, n}-t_{0, n-1}\right)}{2}
$$

Finally, the water content at each reflection boundary can be estimated according to the procedure described in chapter 2 by using $v_{\text {int }}$ in Equation (3). Table 1 summarizes the resulting quantitative estimates derived from the CMP gather discussed in the foregoing section (Figure 5). 
Table 1. Quantitative parameters for five soil layers as estimated by the proposed CMP algorithm.

\begin{tabular}{cccccc}
\hline Soil Layer & Velocity (m/ns) & Travel Time (ns) & Depth(m) & Permittivity & Water Content (Vol.-\%) \\
\hline Layer 1 & 0.0678 & 3.3379 & 0.143 & 19.57 & 34.01 \\
Layer 2 & 0.0618 & 10.3516 & 0.319 & 23.56 & 36.59 \\
Layer 3 & 0.0622 & 20.3595 & 0.633 & 24.26 & 38.28 \\
Layer 4 & 0.0606 & 28.0705 & 0.850 & 24.50 & 39.96 \\
Layer 5 & 0.0598 & 37.8323 & 1.131 & 25.16 & 42.21 \\
\hline \multicolumn{7}{c}{ 1 The real part of the complex permittivity. }
\end{tabular}

\subsection{Airborne and Ground-Based SAR Derived Soil Moisture}

JAXA's second generation airborne polarimetric interferometric L-band synthetic aperture radar started operation in April 2012. The Pi-SAR-L2 system parameters with a center frequency of 1257.5 MHz and a transmission signal bandwidth of $85 \mathrm{MHz}$, are virtually identical to those of ALOS-2/PALSAR-2 for which it served as a pre-launch testbed $[40,41]$. The sensor is mounted on a Gulfstream 2 jet plane with a nominal operating altitude of $12 \mathrm{~km}$. Table 2 gives an overview of the Pi-SAR-L2 overflights with GPR ground campaigns.

Table 2. Overview of SAR datasets and complementary in-situ measurements.

\begin{tabular}{ccccc}
\hline Date & Sensor & Frequency & Polarizations & In-Situ Measurements \\
\hline 8 August 2014 & Pi-SAR-L2 & L-band & HH, HV, VH, VV & TDR, GPR, SR ${ }^{1}$ \\
11 September 2014 & Pi-SAR-L2 & L-band & HH, HV, VH, VV & TDR, GPR, SR \\
12 June 2015 & Pi-SAR-L2 & L-band & HH, HV, VH, VV & TDR, GPR, SR \\
6 August 2015 & Pi-SAR-L2 & L-band & HH, HV, VH, VV & TDR, GPR, SR \\
11 September 2015 & Pi-SAR-L2 & L-band & HH, HV, VH, VV & TDR, GPR, SR \\
30 September 2015 & Pi-SAR-L2 & L-band & HH, HV, VH, VV & TDR, GPR \\
10 November 2015 & GB-SAR & P-band & HH, VV & TDR, GPR, SR \\
11 November 2015 & Pi-SAR-L2 & L-band & HH, HV, VH, VV & TDR, GPR \\
15 April 2016 & GB-SAR & P-band & HH, VV & TDR, GPR, SR \\
\hline
\end{tabular}

${ }^{1} \mathrm{SR}$ indicates surface roughness measurements by using a pin-meter.

The ground-based synthetic aperture radar (GB-SAR) system used in this study is based on a 2-port stepped frequency Vector Network Analyzer (VNA) connected to a low frequency horn antenna with an operating frequency range between approximately 50 and $2000 \mathrm{MHz}$. The antenna is mounted to a positioning system which provides the scanning by moving the antenna along a rail. In the given experiments, the antenna height was fixed at $2 \mathrm{~m}$ and the scan length was $4 \mathrm{~m}$. More details about this system are provided in [42].

A wide variety of microwave backscatter model have been developed to relate soil permittivity, surface roughness, soil texture, incidence angle, polarization and frequency of the radar sensors to observed backscattering coefficients. The approaches range from simple empirical regression models, to comprising semi-empirical models and complex electromagnetic scattering models [43]. Among these, the integral equation model (IEM) proposed by [44] and its further developments known as advance IEM (AIEM) and extended IEM ( $\left.\mathrm{I}^{2} \mathrm{EM}\right)$ have become a popular means to estimate surface soil moisture over bare soil [43,45-48]. Especially when empirical calibrations of the surface roughness are applied [49] the method yields fairly robust results. In this study, we use the $I^{2} E M$ with roughness calibration to retrieve soil moisture from both the L-band and P-band SAR data sets. The results will be discussed and compared to the GPR measurements in the second part of the following section.

\section{Results and Discussion}

The first part of this section will cover the fundamental validation of the proposed method to demonstrate the suitability to provide accurate quantitative in-situ data. In the second part a brief comparison between GPR/CMP and SAR derived soil moisture estimates will be discussed to point out its virtues for calibration and validation purposes. 


\subsection{Validation of the Proposed CMP Method}

To validate the estimation accuracy of the proposed CMP data acquisition and processing scheme, we compare the GPR results with TDR measured soil moisture values. Figure 6 exemplarily shows one vertical soil moisture distribution calculated from the CMP data as compared to that measured by TDR. The reflection layers are well visible in the TDR measurements with $5 \mathrm{~cm}$ spacings. As discussed in Section 3, the GPR reflection occurs in the depth where the contrast in permittivity is largest. Both the picked-up reflection depth as well as the water content from the GPR data agrees well with the TDR result. The quantitative validation of the method is given by the scatterplot showing the comparison between CMP estimates and TDR measurements taken at corresponding depth (Figure 7a). This comparison yields a very good agreement with RMSE of 1.87 Vol.- $\%$. As shown in Figure 7b, the CMP estimated depth of the reflecting layers also agrees well with the different in-situ layer depth measurement. The validation of the depth estimation accuracy yields RMSE of $4.6 \mathrm{~cm}$. These results demonstrate the suitability of the approach to obtain reliable field measurements for SAR studies as well as for hydrological research.

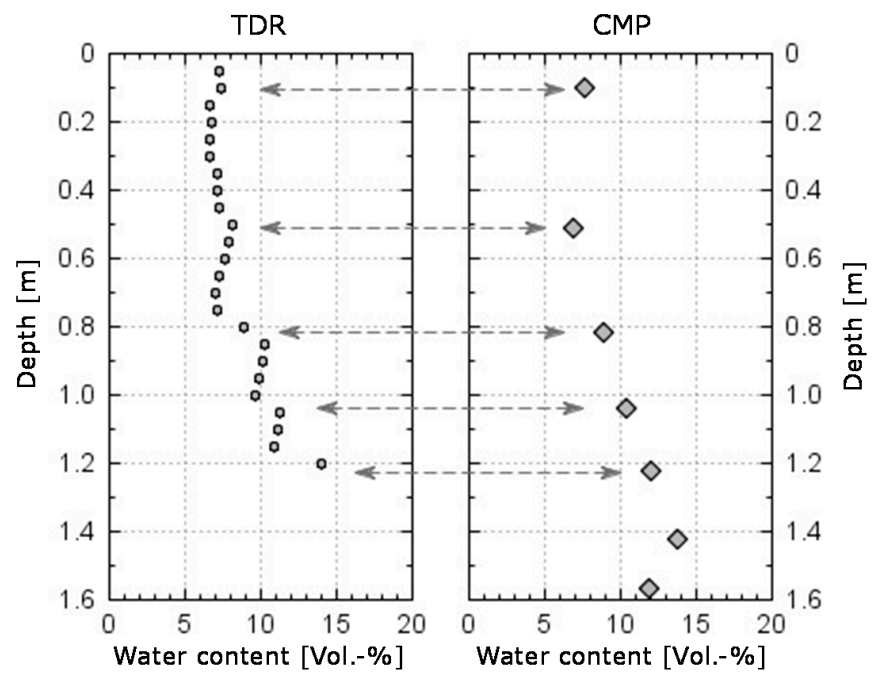

Figure 6. TDR measured vertical soil moisture profile versus CMP estimated water content.

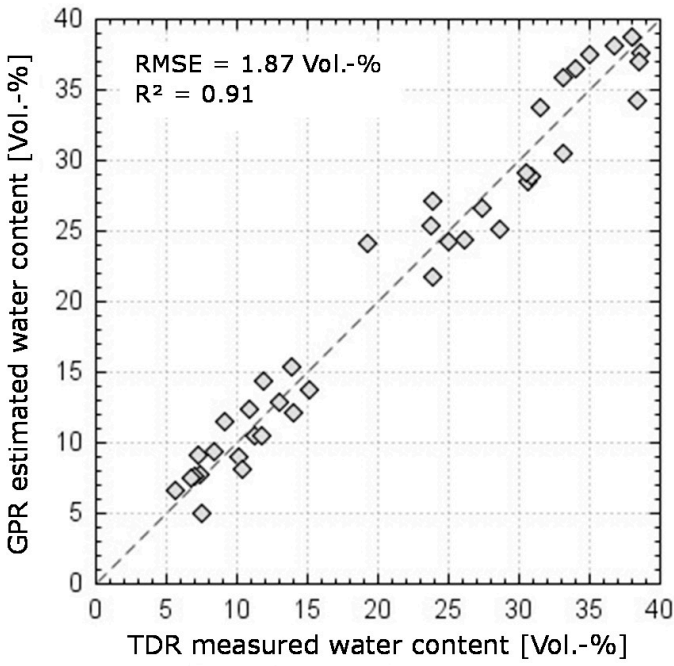

(a)

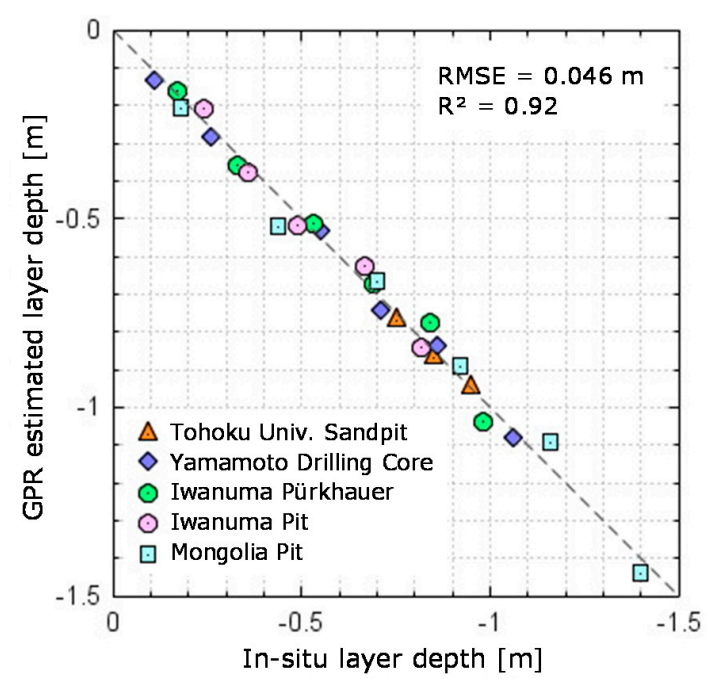

(b)

Figure 7. Comparison of CMP gather derived (a) water content and (b) reflector depth vs. TDR measurements and in-situ depth, respectively. 


\subsection{Comparison of GPR and SAR Derived Soil Moisture Estimates}

Finally, to investigate the potential of the proposed GPR based method for SAR calibration and validation purposes, we carry out a comparison with the L-band and P-band SAR derived soil moisture estimates. Figure 8a shows the GPR results versus the $I^{2} \mathrm{EM}$ results as grey diamonds. Note that in the L-band case we use only value picked up from the reflection layer closest to the surface. For the datasets used in this study the depth of these layers range from 13.9 to $22.8 \mathrm{~cm}$ with an average depth of $17.7 \mathrm{~cm}$. Hence, slightly deeper than the TDR results which represent the average permittivity from 0 to $15 \mathrm{~cm}$ as defined by the length of the rods. For comparison, the TDR results are shown as blue circles. The comparison between I IEM L-band SAR and GPR results yield an RMSE of 1.95 Vol.- $\%$ while that between SAR and TDR results in RMSE of 1.92 Vol.- $\%$. This indicates that both methods are at least comparable at the L-band frequency.

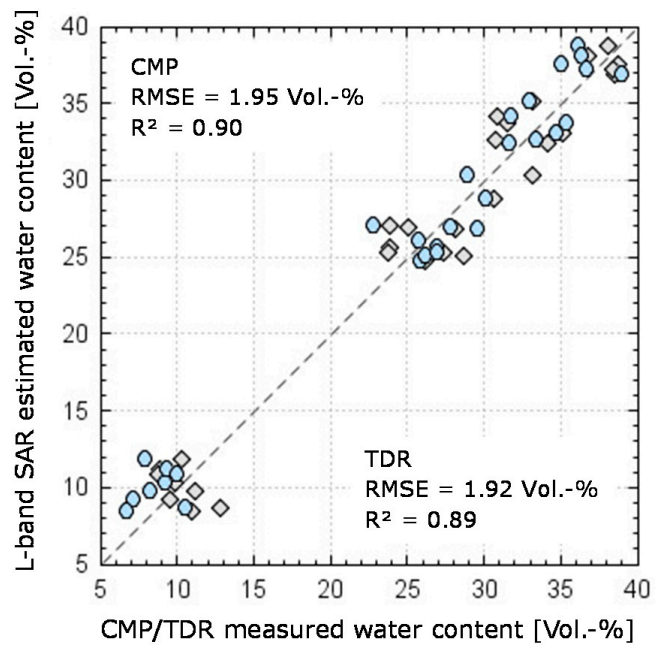

(a)

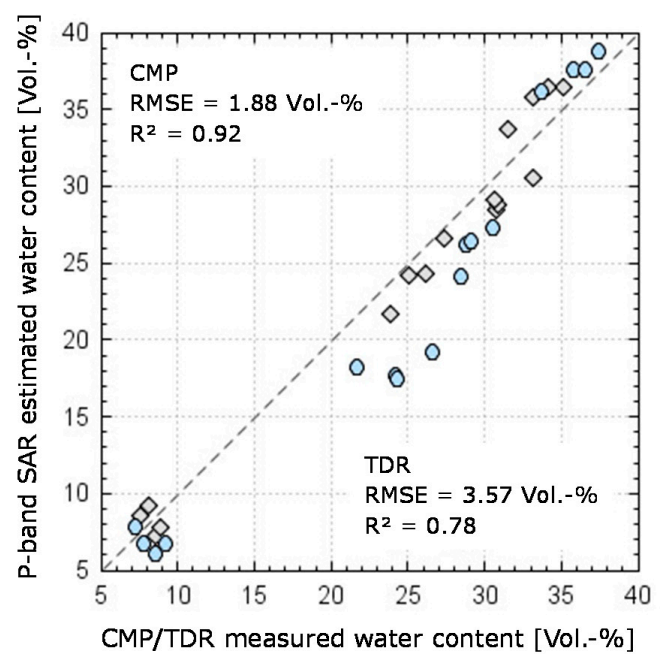

(b)

Figure 8. (a) Comparison of L-band SAR I ${ }^{2} E M$ estimates against CMP and TDR measurements; (b) Comparison of P-band SAR I²EM estimates against CMP and TDR measurements. ( $\diamond=$ GPR; o = TDR).

For the P-band case as shown in Figure 8b, we use only the second reflection layer picked-up from the CMP gather. The soil moisture values represent a depth range from 31.7 to $42.9 \mathrm{~cm}$ with an average of $36.3 \mathrm{~cm}$, thus well below the sensing depth of the TDR probes. As can be seen, the agreement between the I²EM SAR and GPR with RMSE 1.88 Vol.- $\%$ now is much better as compared to the agreement between SAR and TDR with RMSE 3.57 Vol.-\%. This improvement is mainly due to the large mismatch between the near surface permittivity and the below surface permittivity conditions as found for the experiment data points in the range between 20 to $30 \mathrm{Vol.} \%$ where the TDR values significantly overestimate the $\mathrm{I}^{2} \mathrm{EM}$ derived values. In fact, these points represent measurements conditions in which the second layer is dryer than the surface layer. In the experiment, the soil was wetted by sprinkling the surface to simulate rainfall approx. $2 \mathrm{~h}$ prior to the GB-SAR data acquisition. The result was a relatively wet surface over a relatively dryer subsurface, i.e., an inverted moisture profile condition typically found after precipitation events in summer time. Hence, the P-band SAR reflections stemming mostly from the dryer deeper soil layers are not represented well by the wet surface values but agree much better with the lower permittivity found at greater depth. For the other values below 20 Vol.- $\%$ and above 30 Vol.- $\%$, the difference between the water content in the surface layer and the deeper layers was not as pronounced and therefore the improvement by using the GPR method is not that significant. Generally speaking, the larger the contrast in permittivity between the near surface layer and the deeper soil layers, the stronger will the GPR method outperform the TDR method. For such conditions, the virtue of the proposed GPR method is most evident. 
Even though this comparison between SAR derived soil moisture and CMP results is rather simple with a limited observation space, we believe the result sufficiently demonstrates the proposed method's potential to provide accurate in-situ information about the soil moisture states at various depth. Obviously, at P-band the GPR method outperforms the classical surface TDR approach allowing for much more meaningful comparisons between low-frequency SAR data and near-surface geophysical parameters in future studies.

\section{Conclusions}

In this paper, we proposed an improved method for the estimation of vertical soil moisture profiles from multi-offset GPR data. Using a semi-automated data acquisition technique, the time efficiency and accuracy of CMP measurements in the field were drastically improved. Advanced signal processing was applied to yield reliable information about the permittivity and depth of the reflecting soil layers. Based on measurements on a sand beach, the accuracy of the CMP estimates was validated to be in the order of 1.9 Vol.- $\%$ RMSE as compared to TDR measured values. The validation of depth estimation using a variety of in-situ depth measurements gave an RMSE $<5 \mathrm{~cm}$. Both results demonstrate well the accuracy and robustness of the method. With the advanced processing and measurement approach developed in this study the CMP method has become a mature technique to provide quantitative vertical soil moisture distribution. Based on the comparison with SAR derived soil moisture estimates we could show that the GPR/CMP method is well suitable to serve as an in-situ measurement technique for SAR soil moisture studies at low frequencies. The major advantage of the proposed GPR method is the potential to provide fast non-invasive accurate quantitative measurements of vertical soil moisture distribution, taking into account the actual in-situ soil layer structures. Especially at P-band the CMP measurements will be much more useful than the classical TDR measurements performed on the soil surface.

Acknowledgments: We gratefully acknowledge financial supported by the Japan Society for the Promotion of Science (JSPS) under the Grants-in-Aid for Scientific Research Kakenhi (A) 23246076, Kakenhi (S) 25220201 and Kakenhi (B) 15K18075. We thank the Japan Aerospace Exploration Agency (JAXA) for their cooperation and provision of Pi-SAR-L2 data through their PI program. Our thanks are also due to the students who helped in conducting the experiments.

Author Contributions: Christian Koyama developed the measurement method, conducted the experiments, further developed the CMP algorithms, processed and analyzed the GPR and SAR data sets. Hai Liu developed the basic CMP processing scheme and computer codes. Masanobu Shimada and Manabu Watanabe assisted with the Pi-SAR-L2 experiments and data processing. Kazunori Takahashi, Tseedulum Khuut and Motoyuki Sato assisted in improving the signal processing algorithms and computer codes and performed field experiments.

Conflicts of Interest: The authors declare no conflict of interest.

\section{References}

1. Jagdhuber, T.; Hajnsek, I.; Papathanassiou, K.P. An iterative generalized hybrid decomposition for soil moisture retrieval under vegetation cover using fully polarimetric SAR. IEEE J. Sel. Top. Appl. Earth Obs. Remote Sens. 2015, 8, 3911-3922. [CrossRef]

2. Koyama, C.N.; Schneider, K.; Sato, M. Development of a biomass corrected soil moisture retrieval model for dual-polarization ALOS-2 data based on ALOS/PALSAR and Pi-SAR-L2 observations. In Proceedings of the 2015 IEEE International Geoscience and Remote Sensing Symposium (IGARSS), Milan, Italy, 26-31 July 2015; pp. 1316-1319.

3. Bruscantini, C.A.; Konings, A.G.; Narvekar, P.S.; McColl, K.A.; Entekhabi, D.; Grings, F.M.; Karszenbaum, H. L-band radar soil moisture retrieval without ancillary information. IEEE J. Sel. Top. Appl. Earth Obs. Remote Sens. 2015, 8, 5526-5540. [CrossRef]

4. Koyama, C.N.; Korres, W.; Fiener, P.; Schneider, K. Variability of surface soil moisture observed from multitemporal C-band synthetic aperture radar and field data. Vadose Zone J. 2010, 9, 1014-1024. [CrossRef]

5. Paloscia, S.; Pettinato, S.; Santi, E.; Notarnicola, C.; Pasolli, L.; Reppucci, A. Soil moisture mapping using sentinel-1 images: Algorithm and preliminary validation. Remote Sens. Environ. 2013, 134, 234-248. [CrossRef] 
6. Bai, X.J.; He, B.B.; Li, X.W. Optimum surface roughness to parameterize advanced integral equation model for soil moisture retrieval in prairie area using Radarsat-2 data. IEEE Trans. Geosci. Remote Sens. 2016, 54, 2437-2449. [CrossRef]

7. Baghdadi, N.; Aubert, M.; Zribi, M. Use of TerraSAR-X data to retrieve soil moisture over bare soil agricultural fields. IEEE Geosci. Remote Sens. Lett. 2012, 9, 512-516. [CrossRef]

8. Gupta, D.K.; Prasad, R.; Kumar, P.; Vishwakarma, A.K. Soil moisture retrieval using ground based bistatic scatterometer data at X-band. Adv. Space Res. 2017, 59, 996-1007. [CrossRef]

9. Jagdhuber, T.; Hajnsek, I.; Caputo, M.; Papathanassiou, K.P. Dual-polarimetry for soil moisture inversion at X-band. In Proceedings of the EUSAR 2014, 10th European Conference on Synthetic Aperture Radar, Berlin, Germany, 3-5 June 2014.

10. Arcioni, M.; Bensi, P.; Fehringer, M.; Fois, F.; Hélière, F.; Lin, C.C.; Scipal, K. The biomass mission, status of the satellite system. In Proceedings of the 2014 IEEE Geoscience and Remote Sensing Symposium, Quebec City, QC, Canada, 13-18 July 2014; pp. 1413-1416.

11. Yilmaz, O. Seismic Data Analysis: Processing, Inversion, and Interpretation of Seismic Data; SEG Books: Tusla, OK, USA, 2003.

12. Daniels, D.J. Ground Penetrating Radar, 2nd ed.; Institution of Engineering and Technology: London, UK, 2007.

13. Huisman, J.A.; Hubbard, S.S.; Redman, J.D.; Annan, A.P. Measuring soil water content with ground penetrating radar: A review. Vadose Zone J. 2003, 2, 476-491. [CrossRef]

14. Weiler, K.W.; Steenhuis, T.S.; Boll, J.; Kung, K.J.S. Comparison of ground penetrating radar and time-domain reflectometry as soil water sensors. Soil Sci. Soc. Am. J. 1998, 62, 1237-1239. [CrossRef]

15. Robinson, D.A.; Campbell, C.S.; Hopmans, J.W.; Hornbuckle, B.K.; Jones, S.B.; Knight, R.; Ogden, F.; Selker, J.; Wendroth, $\mathrm{O}$. Soil moisture measurement for ecological and hydrological watershed-scale observatories: A review. Vadose Zone J. 2008, 7, 358-389. [CrossRef]

16. Vereecken, H.; Huisman, J.A.; Bogena, H.; Vanderborght, J.; Vrugt, J.A.; Hopmans, J.W. On the value of soil moisture measurements in vadose zone hydrology: A review. Water Resour. Res. 2008, 44. [CrossRef]

17. Minet, J.; Bogaert, P.; Vanclooster, M.; Lambot, S. Validation of ground penetrating radar full-waveform inversion for field scale soil moisture mapping. J. Hydrol. 2012, 424, 112-123. [CrossRef]

18. Ardekani, M.R.M. Off- and on-ground GPR techniques for field-scale soil moisture mapping. Geoderma 2013, 200, 55-66. [CrossRef]

19. Huisman, J.A.; Snepvangers, J.J.J.C.; Bouten, W.; Heuvelink, G.B.M. Mapping spatial variation in surface soil water content: Comparison of ground-penetrating radar and time domain reflectometry. J. Hydrol. 2002, 269, 194-207. [CrossRef]

20. Weihermuller, L.; Huisman, J.A.; Lambot, S.; Herbst, M.; Vereecken, H. Mapping the spatial variation of soil water content at the field scale with different ground penetrating radar techniques. J. Hydrol. 2007, 340, 205-216. [CrossRef]

21. Bevan, M.J.; Endres, A.L.; Rudolph, D.L.; Parkin, G. The non-invasive characterization of pumping-induced dewatering using ground penetrating radar. J. Hydrol. 2003, 281, 55-69. [CrossRef]

22. Lu, Q.; Sato, M. Estimation of hydraulic property of an unconfined aquifer by GPR. Sens. Imaging Int. J. 2007, 8, 83-99. [CrossRef]

23. Turesson, A. Water content and porosity estimated from ground-penetrating radar and resistivity. J. Appl. Geophys. 2006, 58, 99-111. [CrossRef]

24. Mayne, W.H. Common reflection point horizontal data stacking techniques. Geophysics 1962, 27, $927-938$. [CrossRef]

25. Duncan, G.; Beresford, G. Some analyses of 2-d median f-k filters. Geophysics 1995, 60, 1157-1168. [CrossRef]

26. Dix, C.H. Seismic velocities from surface measurements. Geophysics 1955, 20, 68-86. [CrossRef]

27. Liu, H.; Yokota, Y.; Takahashi, K.; Sato, M. Monitoring of dynamic groundwater level change by ground penetrating radar for quantitative estimation of hydraulic parameters. In Proceedings of the 2012 IEEE International Geoscience and Remote Sensing Symposium, Munich, Germany, 22-27 July 2012; pp. 3214-3217.

28. Greaves, R.J.; Lesmes, D.P.; Lee, J.M.; Toksoz, M.N. Velocity variations and water content estimated from multi-offset, ground-penetrating radar. Geophysics 1996, 61, 683-695. [CrossRef]

29. Nakashima, Y.; Zhou, H.; Sato, M. Estimation of groundwater level by GPR in an area with multiple ambiguous reflections. J. Appl. Geophys. 2001, 47, 241-249. [CrossRef] 
30. Sato, M.; Koyama, C.N. Fundamental survey on the microwave soil moisture measurement. In Proceedings of the International Workshop on Terrestrial Change in Mongolia, Tokyo, Japan, 20-21 December 2013; pp. 26-30.

31. Topp, G.C.; Davis, J.L.; Annan, A.P. Electromagnetic determination of soil-water content - measurements in coaxial transmission-lines. Water Resour. Res. 1980, 16, 574-582. [CrossRef]

32. Davis, J.L.; Annan, A.P. Ground-penetrating radar for high-resolution mapping of soil and rock stratigraphy. Geophys. Prospect. 1989, 37, 531-551. [CrossRef]

33. Koyama, C.N.; Sato, M. Estimation of soil moisture and debris pile volume from Pi-SAR2X and Pi-SAR-L2 square-flight data. In Proceedings of the 2014 IEEE Geoscience and Remote Sensing Symposium, Quebec City, QC, Canada, 13-18 July 2014; pp. 1516-1519.

34. Fisher, S.C.; Stewart, R.R.; Jol, H.M. Ground penetrating radar (GPR) data enhancement using seismic techniques. J. Environ. Eng. Geophys. 1996, 1, 89-96. [CrossRef]

35. Steelman, C.M.; Endres, A.L. Assessing vertical soil moisture dynamics using multi-frequency GPR common-midpoint soundings. J. Hydrol. 2012, 436, 51-66. [CrossRef]

36. Sato, M.; Liu, H.; Komagino, T.; Takahashi, K. Archaeological survey by gpr for recovery from 3.11 great earthquake and tsunami in east Japan. In Proceedings of the 15th International Conference on Ground Penetrating Radar, Brussels, Belgium, 30 June-4 July 2014; pp. 25-30.

37. Neidell, N.S.; Taner, M.T. Semblance and other coherency measures for multichannel data. Geophysics 1971, 36, 482-497. [CrossRef]

38. Liu, H.; Sato, M. Dynamic groundwater level estimation by the velocity spectrum analysis of GPR. In Proceedings of the 2012 14th International Conference on Ground Penetrating Radar (GPR), Shanghai, China, 4-8 June 2012; pp. 413-418.

39. Booth, A.D.; Clark, R.; Murray, T. Semblance response to a ground-penetrating radar wavelet and resulting errors in velocity analysis. Near Surf. Geophys. 2010, 8, 235-246. [CrossRef]

40. Shimada, M.; Kawano, N.; Watanabe, M.; Motooka, T.; Ohki, M. Calibration and validation of the Pi-SAR-L2. In Proceedings of the 2013 Asia-Pacific Conference on Synthetic Aperture Radar, Tsukuba, Japan, 23-27 September 2013; pp. 194-197.

41. Shimada, M.; Watanabe, M.; Motooka, T.; Kankaku, Y. PALSAR-2 polarimetric performance and the simulation study using the Pi-SAR-L2. In Proceedings of the 2013 IEEE International Geoscience and Remote Sensing Symposium, Melbourne, Australia, 21-26 July 2013; pp. 2309-2312.

42. Koyama, C.N.; Sato, M. Detection and classification of subsurface objects by polarimetric radar imaging. In Proceedings of the 2015 IEEE Radar Conference, Johannesburg, South Africa, 27-30 October 2015; pp. 440-445.

43. Ulaby, F.T.; Long, D.G. Microwave Radar and Radiometric Remote Sensing; University of Michigan Press: Ann Arbor, MI, USA, 2014.

44. Fung, A.K.; Li, Z.; Chen, K.S. Backscattering from a randomly rough dielectric surface. IEEE Trans. Geosci. Remote Sens. 1992, 30, 356-369. [CrossRef]

45. Chen, K.S.; Tzong-Dar, W.; Mu-King, T.; Fung, A.K. Note on the multiple scattering in an IEM model. IEEE Trans. Geosci. Remote Sens. 2000, 38, 249-256. [CrossRef]

46. Tzong-Dar, W.; Chen, K.S.; Jiancheng, S.; Fung, A.K. A transition model for the reflection coefficient in surface scattering. IEEE Trans. Geosci. Remote Sens. 2001, 39, 2040-2050. [CrossRef]

47. Chen, K.S.; Tzong-Dar, W.; Leung, T.; Qin, L.; Jiancheng, S.; Fung, A.K. Emission of rough surfaces calculated by the integral equation method with comparison to three-dimensional moment method simulations. IEEE Trans. Geosci. Remote Sens. 2003, 41, 90-101. [CrossRef]

48. Fung, A.K.; Chen, K.S. An update on the IEM surface backscattering model. IEEE Geosci. Remote Sens. Lett. 2004, 1, 75-77. [CrossRef]

49. Baghdadi, N.; Gherboudj, I.; Zribi, M.; Sahebi, M.; King, C.; Bonn, F. Semi-empirical calibration of the IEM backscattering model using radar images and moisture and roughness field measurements. Int. J. Remote Sens. 2004, 25, 3593-3623. [CrossRef]

(C) 2017 by the authors. Licensee MDPI, Basel, Switzerland. This article is an open access article distributed under the terms and conditions of the Creative Commons Attribution (CC BY) license (http://creativecommons.org/licenses/by/4.0/). 